Supporting Information

\title{
Solvent tuning the selective hydrogenation of levulinic acid into biofuels over Ni-metal organic framework derived catalyst
}

Hong $\mathrm{Xu}^{\dagger}$, Di Hü,t, Zixiao $\mathrm{Yi}^{\dagger}$, Zuotong $W u^{\dagger}$, Man Zhang ${ }^{\dagger}$ and Kai Yan ${ }^{*}, *$

†School of Environmental Science and Engineering, Sun Yat-sen University, 135 Xingang Xi Road, Guangzhou 510275, P. R. China

¥Guangdong Provincial Key Laboratory of Environmental Pollution Control and Remediation Technology, Guangzhou 510275, P. R. China

*Corresponding author Email address: yank9@mail.sysu.edu.cn.

KEYWORDS: solvent effects, levulinic acid, tune, gamma-valerolactone, valerate esters.

\section{Experimental methods:}

Chemicals and materials. The reagent supplies used in the experiment include nickel nitrate hexahydrate $\left(\mathrm{Ni}\left(\mathrm{NO}_{3}\right)_{2} \cdot 6 \mathrm{H}_{2} \mathrm{O},>98 \%\right), 1,3,5$-benzenetricarboxylic $\left(\mathrm{H}_{3} \mathrm{BTC}, 98 \%\right)$ and methanol anhydrous $\left(\mathrm{CH}_{3} \mathrm{OH}\right)$, which were acquired from shanghai Macklin Biochemical, China. Five types of solvents including 1,4-dioxane, methanol, ethanol, isopropanol and tetrahydrofuran (analytical grade, acquired from Guangzhou 
chemical regent factory). All chemicals were purchased from commercial sources and used without further treatments.

Preparation of Ni-MOFs. In a typical hydrothermal synthesis of Ni-BTC MOFs, 8 mmol nickel nitrate $\left(\mathrm{Ni}\left(\mathrm{NO}_{3}\right)_{2} \cdot 6 \mathrm{H}_{2} \mathrm{O}\right)$ and $4.8 \mathrm{mmol}$ 1,3,5-benzenetricarboxylic acid $\left(\mathrm{H}_{3} \mathrm{BTC}\right)$ were dissolved in $140 \mathrm{~mL}$ of methanol. The mixture was stirred for 2 hours at room temperature to form a green transparent solvent, and then transferred to a Teflon-lined stainless steels autoclave with a volume capacity of $200 \mathrm{~mL}$ and heated at $150^{\circ} \mathrm{C}$ in water-bath for $24 \mathrm{~h}$. After the heat treatment, the autoclave was allowed to room temperature and a green powder was collected from the supernatant solution by centrifugation at a speed of $10000 \mathrm{rpm}$. Then the product was washed with absolute methanol several times, and dried in a vacuum oven at $60^{\circ} \mathrm{C}$ overnight.

Preparation of $\mathbf{N i} / \mathbf{C}$ catalysts. The obtained Ni-MOF green powder was placed in a tube furnace, pyrolyzed at a setting temperature $\left(400-600^{\circ} \mathrm{C}\right)$ at a heating rate of 1 ${ }^{\circ} \mathrm{C} / \mathrm{min}$ in flowing $\operatorname{Ar}(40 \mathrm{~mL} / \mathrm{min})$. The specific heating procedure is: hating up to $200^{\circ} \mathrm{C}$ at $1{ }^{\circ} \mathrm{C} / \mathrm{min}$ from room temperature first, keep 3 hours and then heating up to $500^{\circ} \mathrm{C}$ at $1^{\circ} \mathrm{C} / \mathrm{min}$, keep 3 hours as before, cooling to room temperature finally. The obtained catalyst was simply named as $\mathrm{Ni} / \mathrm{C}-\mathrm{x}$, where $\mathrm{x}$ represents the pyrolysis temperature.

Levulinic acid hydrogenation. Levulinic acid hydrogenation reactions were carried out in a $100 \mathrm{~mL}$ stainless steel autoclave with a mechanical stirrer. In a typical conversion, $0.5 \mathrm{~g}$ levulinic acid and $20 \mathrm{~mL}$ organic solvent (dioxane, $\geq 99.5 \%$, 
Guangdong chemical reagent) were mixed together with $100 \mathrm{mg} \mathrm{Ni} / \mathrm{C}$ catalyst, and then the mixture was loaded into the reactor. The reactor should be purged by flowing Argon (Ar) 3 times to remove residual oxygen firstly, and then $\mathrm{H}_{2}$ was pressurized into this vessel, heated to the scheduled temperature $\left(160^{\circ} \mathrm{C}-220^{\circ} \mathrm{C}\right)$ with a proper stirring speed of $600 \mathrm{rpm}$. The catalysts were isolated from the reaction solution by magnetic separation at the end of the reaction, washed with ethanol several times, and then heated at $50{ }^{\circ} \mathrm{C}$ under vacuum for $6 \mathrm{~h}$.

LA conversion, GVL selectivity and productivity were calculated according to Equations (1) to (3):

LA conversion $(\%)=1-\left(\frac{\text { Remaining amount of } L A}{\text { Initial amount of } L A}\right) \times 100 \%$;

GVL selectivity $(\%)=\frac{\text { Amount of GVL }}{\text { Sum amount of products }} \times 100 \%$;

GVL yield $(\%)=\frac{\text { Amount of } G V L}{\text { Inicial amount of } L A} \times 100 \%$.

Gas chromatograph test. After catalytic hydrogenation of levulinic acid under Ni/C nanoparticles, the autoclave was natural cooling to room temperature, the products were filtered using a $0.22 \mu \mathrm{m}$ microporous membrane filter and then analyzed by gas chromatograph (GC, Techcomp 7900) equipped with a capillary column (TM-FFAP) of $30 \mathrm{~m}$ length) and a flame ionization detector (FID). The effect of internal diffusion is not considered and the elimination of the external diffusion effect can be achieved by increasing the rotation speed for the conversion of levulinic acid achieved 100\% under the stirring speed of $600 \mathrm{rpm}$. 


\section{Characterization methods:}

X-ray diffraction (XRD). XRD measurement was used to acquire atomic or molecular structures and morphologies by analyzing diffraction patterns of the catalysts. It was carried out with a diffractometer using nickel-filtered $\mathrm{Cu} \mathrm{K} \alpha$ radiation $(\lambda=0.15418 \mathrm{~nm})$, operated at $40 \mathrm{kV}$ and $40 \mathrm{~mA}$. (Ni-MOF: scanning angle $(2 \theta)$ of $3^{\circ}-$ $50^{\circ}, 5^{\circ} \mathrm{min}^{-1}, \mathrm{Ni} / \mathrm{C}$ nanoparticles: scanning angle $(2 \theta)$ of $\left.5^{\circ}-80^{\circ}, 10^{\circ} \mathrm{min}^{-1}\right)$.

X-ray photoelectron spectroscopy (XPS). XPS analysis was measured on a thermo ESCALAB 250 photoelectron instrument (Thermo, USA) equipped with Al Ka (1846.6 $\mathrm{eV}$ ) source, operated at $150^{\circ} \mathrm{C}$ and $10.8 \mathrm{~mA}$. The part spectrums were dealt with XPSpeak-differentation-imitating analyzing and spectrum correction according to $\mathrm{C} 1 \mathrm{~s}$ at $284.8 \mathrm{eV}$.

Scanning electron microscope (SEM). SEM images were obtained with a HitachiE3500 to elucidate the morphologies of the samples.

Transmission electron microscope (TEM). The size and morphology of $\mathrm{Ni} / \mathrm{C}$ nanoparticles were investigated by using a transmission electron microscope (TEM, JEOL, JEM-2010HR) with EDS analysis (Oxford INCA EDS) operated at $300 \mathrm{kV}$. EDS analysis demonstrated the presence of zero-valent $\mathrm{Ni}$ in $\mathrm{Ni} / \mathrm{C}$ catalysts.

Thermogravimetric analysis (TGA). The thermal behavior of Ni-MOFs was tested by TG analysis (TGA5500) from room temperature to $750^{\circ} \mathrm{C}$ under $\mathrm{N}_{2}$ atmosphere, with a heating rate of $10{ }^{\circ} \mathrm{C} / \mathrm{min}$. 
$\mathbf{N H}_{3}$-temperature-programmed desorption $\mathbf{( N H}_{3}$-TPD). Relative acid strength and acid amount were gotten by $\mathrm{NH}_{3}-\mathrm{TPD}$ and it was conducted on Quantachrome autosorb iQ equipment (Quantachrome, USA) with the heating rate of $10{ }^{\circ} \mathrm{C} / \mathrm{min}$.

Inductively coupled plasma-atomic emission spectrometry (ICP-AES). The actual nickel loadings of Ni/C-500 catalysts were determined by Inductively Coupled Plasma (ICP) on an IRIS (HR) instrument from TJA corporation. Before analysis, proper amount powder sample was treated by hot aqua regia (the volume ratio of $\mathrm{HCl}$ and $\mathrm{HNO}_{3}$ is $3: 1$ ) at a constant temperature of $260^{\circ} \mathrm{C}$.

Nitrogen sorption isotherms. Nitrogen sorption isotherms of $\mathrm{Ni} / \mathrm{C}$ catalysts were performed at $-196^{\circ} \mathrm{C}$ on Quantachrome instrument (Autosorb-iQ Automate Surface Area \& Pore Size Analyzer) under nitrogen atmosphere, which would be helpful to further understand specific surface area and pore structure characteristics of the materials. Brunauer-Emmett-Teller (BET) method was appropriate for calculating the total surface area within the relative pressure $\left(\mathrm{P} / \mathrm{P}_{0}\right)$ range from 0.01 to 0.25 . t-plot method is used to calculate the specific surface area of the micropores in the sample. Pore size distribution was obtained with the Barrett-Joyner-Halenda (BJH).

FT-IR spectrum. It is developed based on the principle of Fourier Transform after interference, actually composed with Michelson interferometer and computer. Different peak positions correspond to different products species according to FT-IR spectrum, the reaction path and the mechanism followed by the catalytic reaction can be predicted. 
In this work, Bruker optics (VERTEX 70) is used to examine the internal structure and functional groups of the crystal for verifying the synthesis process of catalysts. $\mathrm{KBr}$ is added for tablet and the scanning range is from $4000-400 \mathrm{~cm}^{-1}$.

$\mathbf{H}_{2}$-temperature programmed reduction $\left(\mathbf{H}_{2}\right.$-TPR). It was conducted on AutoChem1 II 2920 equipped with TCD detector in order to determine differences in reducibility. $100 \mathrm{mg}$ fresh powder catalyst was heated from room temperature to $150^{\circ} \mathrm{C}$ for 2 hours in order to remove unstable adsorbed species, then cooled down to $50^{\circ} \mathrm{C}$ under He inert gas atmosphere. Subsequently, the sample was treated with $10 \% \mathrm{Ar} / \mathrm{H}_{2}$ $\left(50{ }^{\circ} \mathrm{C} / \mathrm{min}\right.$ ) for $0.5 \mathrm{~h}$ to ensure stability of baseline and then increase the temperature to $800^{\circ} \mathrm{C}\left(10^{\circ} \mathrm{C} / \mathrm{min}\right)$. The reduction process can be measured with the hydrogen consumption.

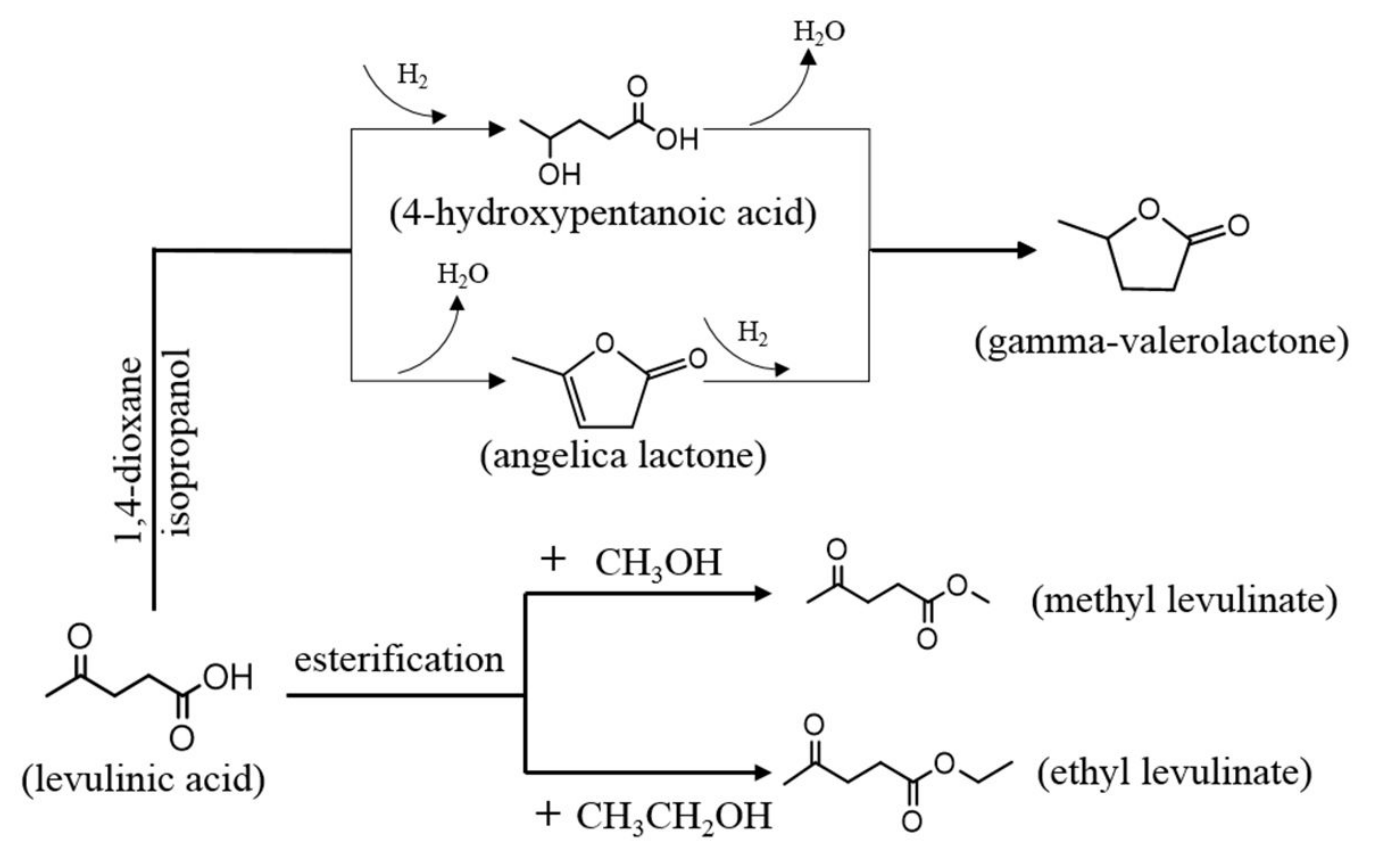

Scheme S1. Products distribution in the hydrogenation of levulinic acid over various solvents. 
Characterization of Ni-BTC precursor.

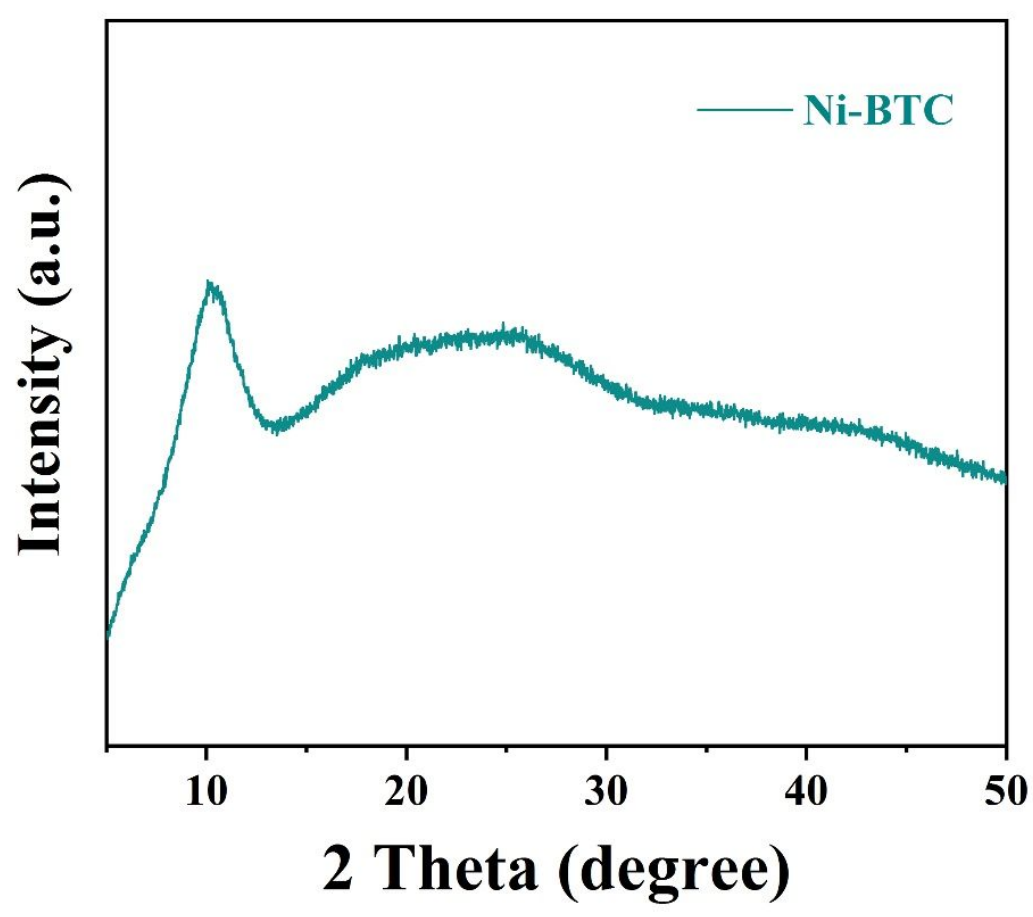

Figure S1. Powder XRD profile of Ni-BTC. which reveals its amorphous crystalline characteristic. 


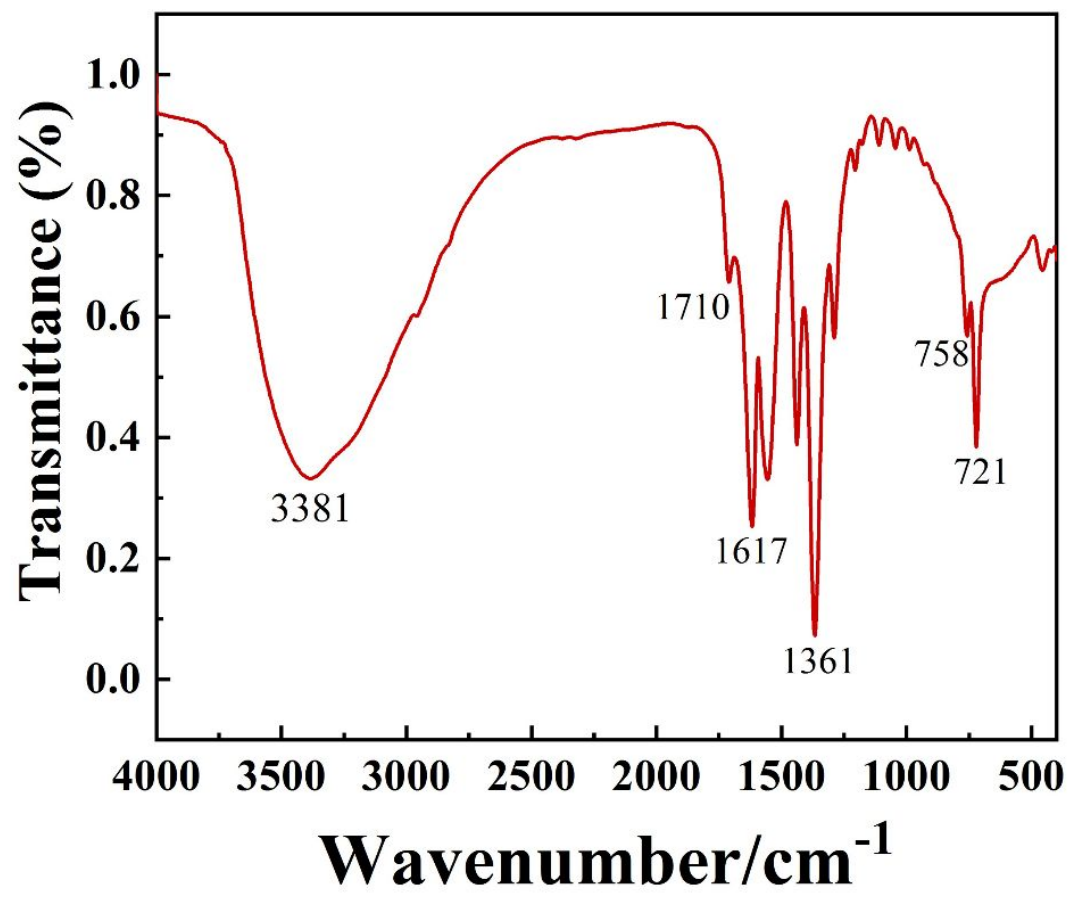

Figure S2. The FT-IR spectrum of Ni-BTC. Scanning range is $4000-400 \mathrm{~cm}^{-1}$. The broad adsorption band observed at $3381 \mathrm{~cm}^{-1}$ is associated with the stretching vibrations of the coordinated water molecules, mainly for the -OH group and the strong band at $1617 \mathrm{~cm}^{-1}$ illustrates the deprotonated of carboxyl group 


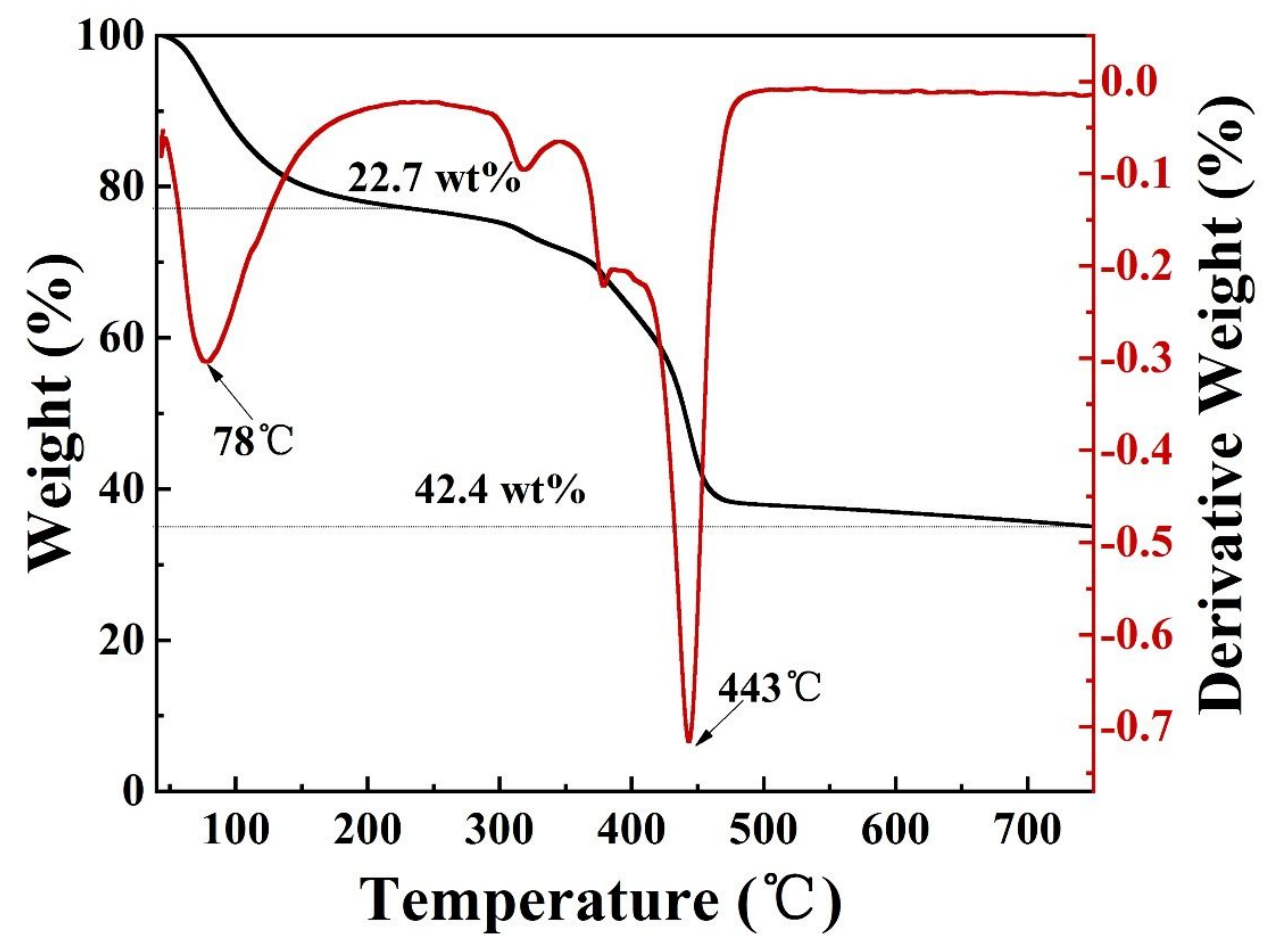

Figure S3. TGA curves of Ni-BTC. The thermal behavior of Ni-BTC was investigated by TG analysis, the first-stage occurred at room temperature to $220^{\circ} \mathrm{C}$ was attributed to the loss of lattice water, lead to a weight loss of $22.7 \mathrm{wt} \%$; while the second stage with the weight decreeing $42.4 \mathrm{wt} \%$ can be ascribed to the decomposition of the organic ligand from Ni-MOFs precursor with the pyrolysis temperature to $470^{\circ} \mathrm{C}$. Compared to the TG curve, the dramatic thermogravimetric curve (DTC) can distinguish successive thermogravimetric changes accurately including reaction start-end temperature and the temperature at maximum reaction rate. Actually, the second stage can be described to three continuous pyrolysis processes and the corresponding temperatures at maximum reaction rate are $318^{\circ} \mathrm{C}, 379^{\circ} \mathrm{C}$ and $443^{\circ} \mathrm{C}$ respectively. 


\section{Characterization of $\mathrm{Ni} / \mathrm{C}$ nanocatalysts.}
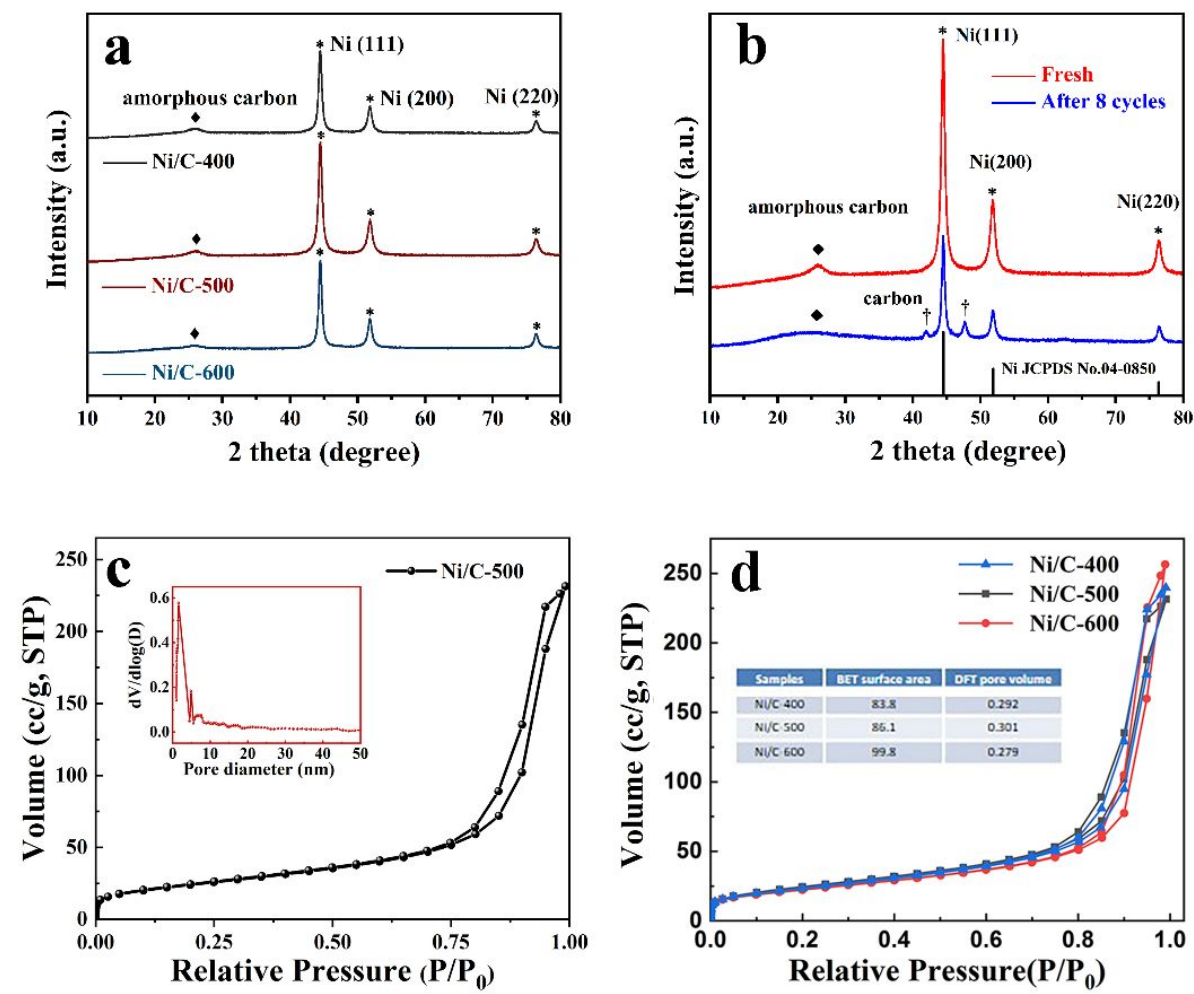

Figure S4. (a) XRD patterns of Ni/C catalysts pyrolyzed in different temperatures; (b) XRD profile of $\mathrm{Ni} / \mathrm{C}-500$ catalyst before and after LA hydrogenation reaction. (conditions: $473 \mathrm{~K}, 5 \mathrm{~h}, 1 \mathrm{MPa} \mathrm{H}_{2}, 0.5 \mathrm{~g}$ levulinic acid and $100 \mathrm{mg} \mathrm{Ni} / \mathrm{C}-500$ catalysts, $20 \mathrm{~mL}$ 1,4-dioxane solvent), the $\mathrm{Ni} / \mathrm{C}-500$ catalysts remained crystalline structure and a small amount of carbon formed after eight cycles; (c) $\mathrm{N}_{2}$ adsorption/desorption isotherms and pore size distribution of Ni/C-500; (d) $\mathrm{N}_{2}$ adsorption and desorption isotherms of $\mathrm{Ni} / \mathrm{C}$ catalysts pyrolyzed in different temperatures. 

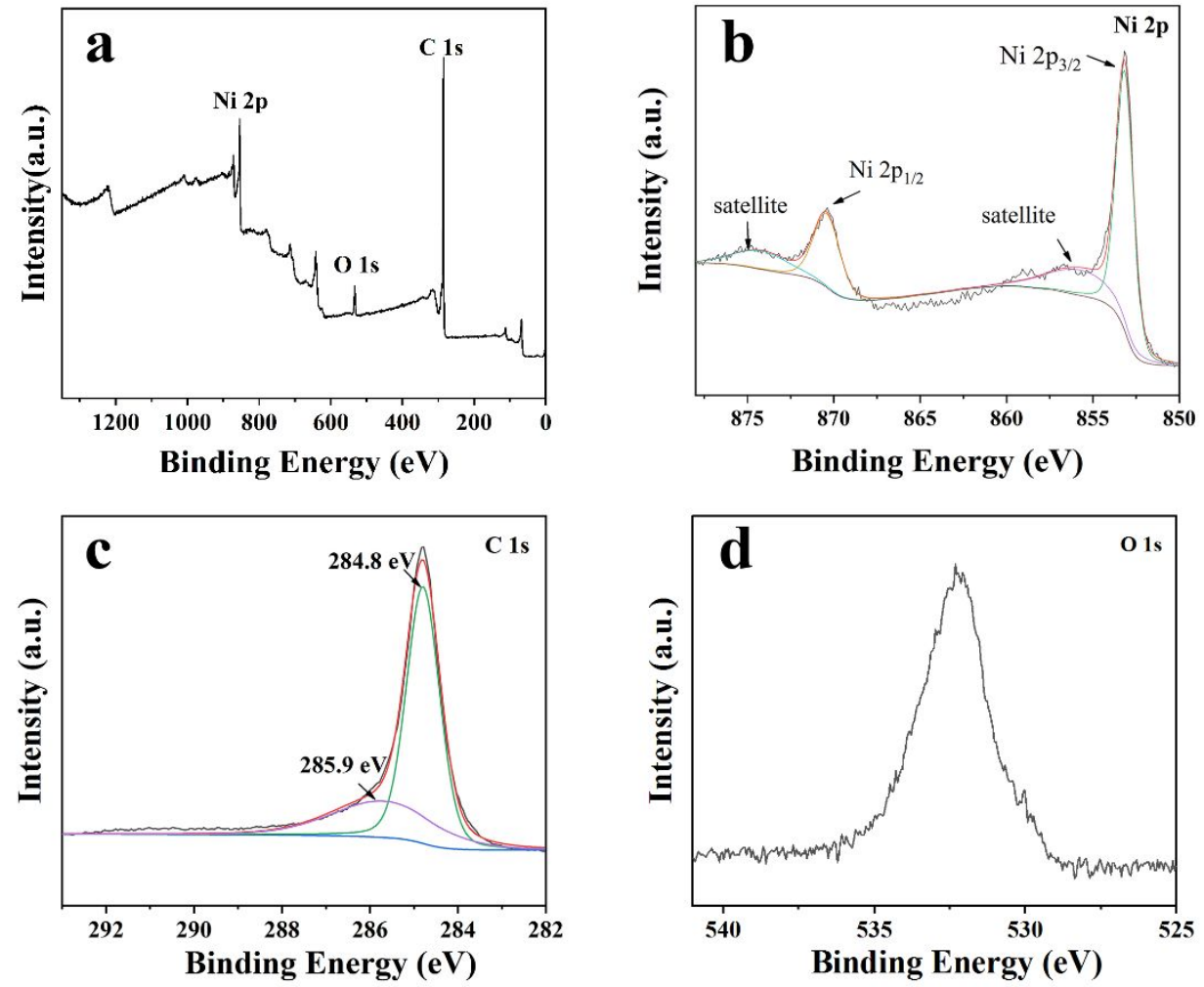

Figure S5. The XPS spectra of the Ni/C-500 nanocatalyst. 


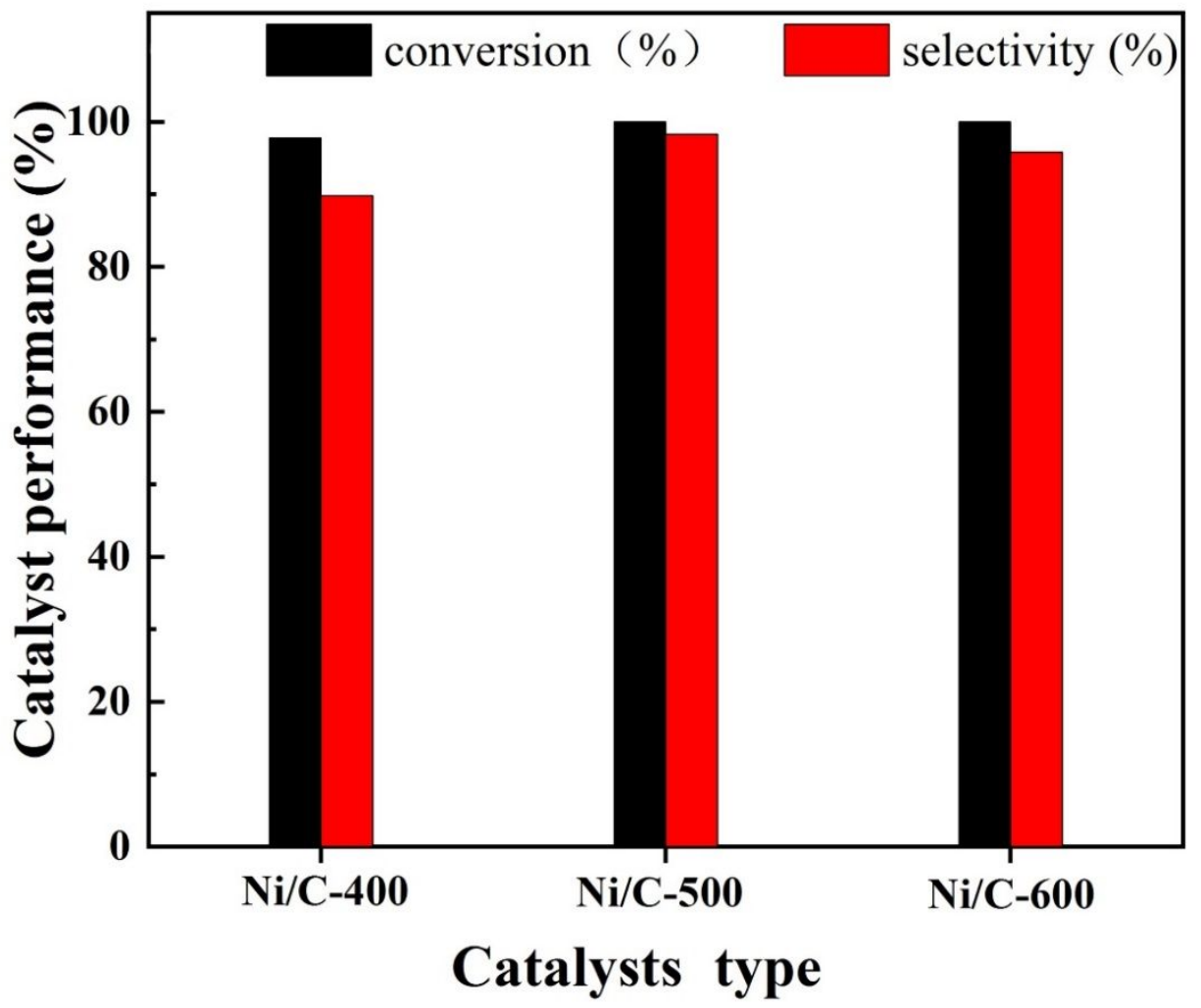

Figure S6. Catalytic performance of pyrolyzed samples with different temperatures. 


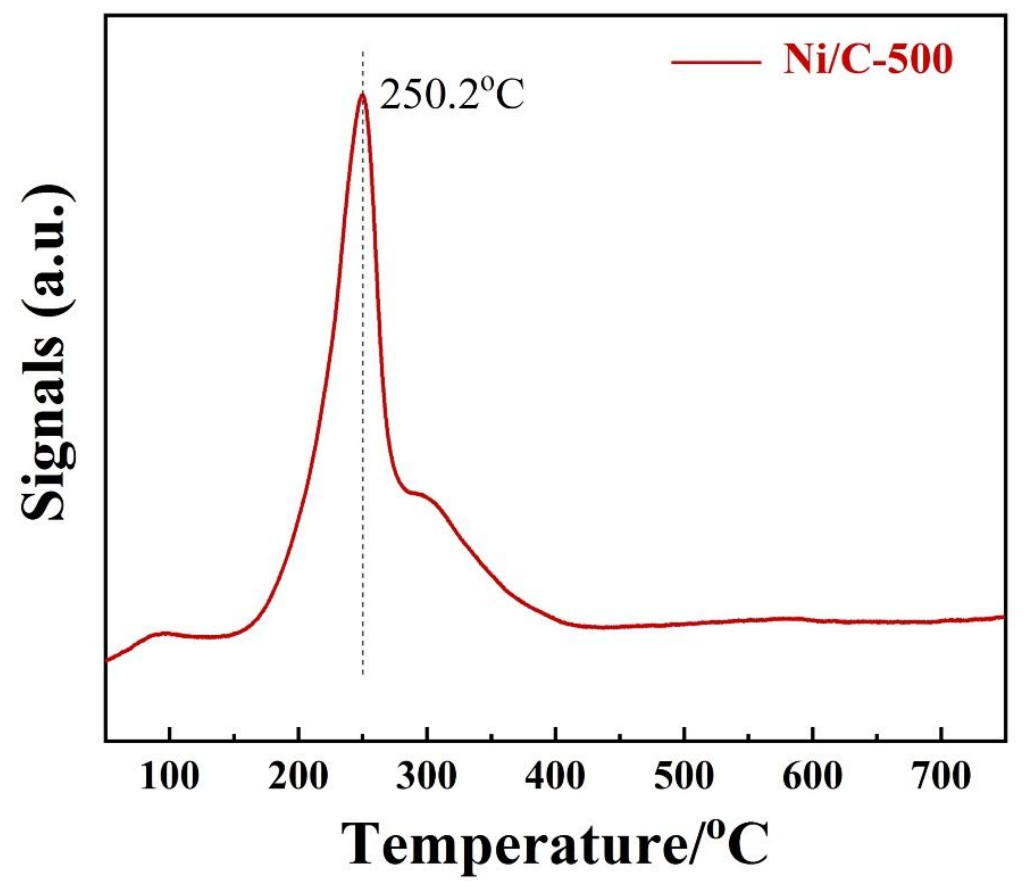

Figure $\mathbf{S 7} . \mathrm{NH}_{3}-\mathrm{TPD}$ spectra of $\mathrm{Ni} / \mathrm{C}-500$ catalyst. The temperature of $250.2^{\circ} \mathrm{C}$ indicated that the weak acid site of catalyst facilitates the hydrogenation process. 

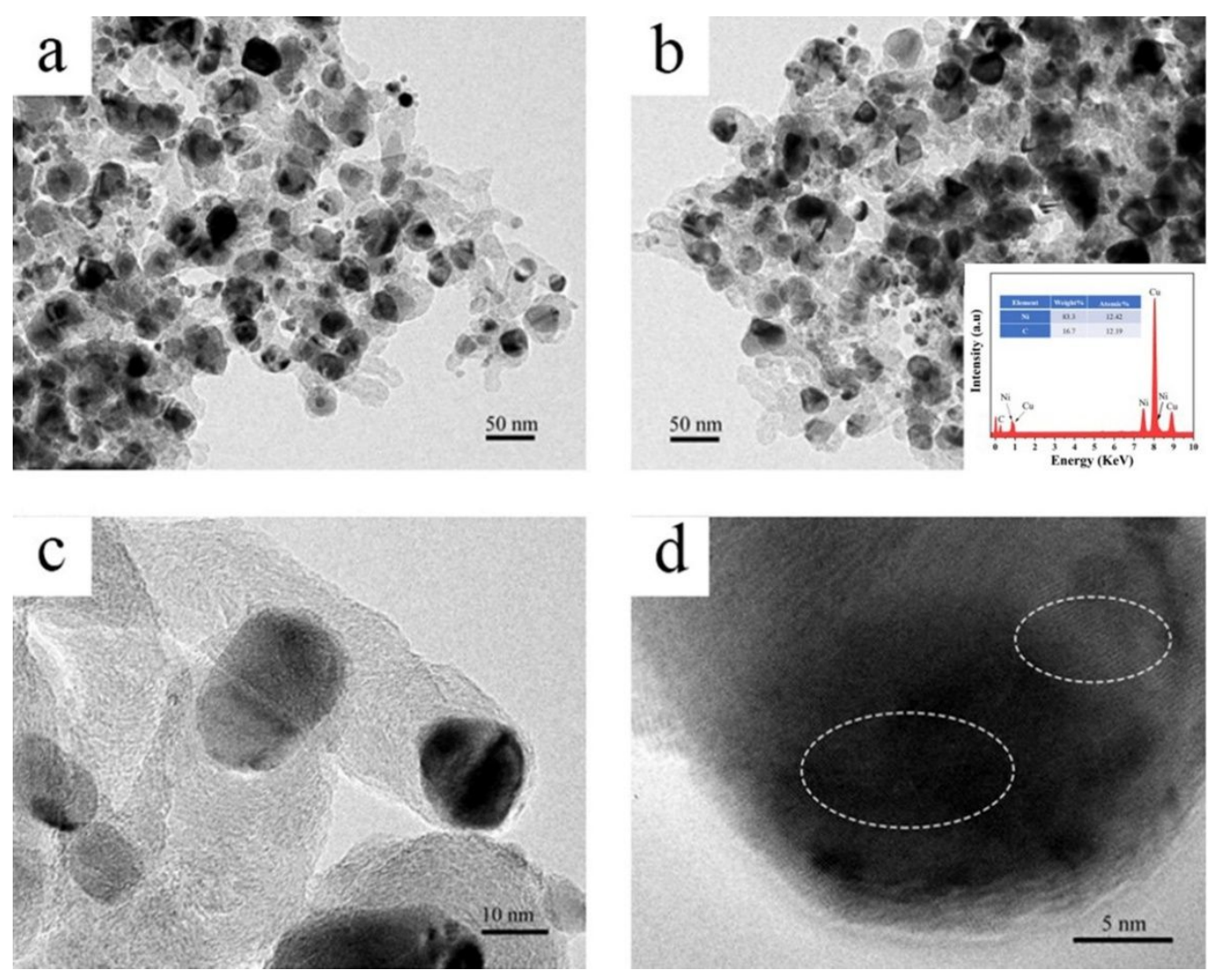

Figure S8. TEM images of Ni/C-500 catalyst. ( $a, b$ and c) shows the morphology and particle size distribution of catalyst and the EDS distribution of elements; (d) The picture with several small crystal particles.

Table S1. The result of XPS analysis.

\begin{tabular}{ccc}
\hline Entry & Peak BE $(\mathrm{eV})$ & FWHM \\
\hline Ni 2p & 853.08 & 2.512 \\
C 1s & 284.08 & 1.634 \\
O 1s & 531.08 & 3.291 \\
\hline
\end{tabular}


Table S2. Conversion and selectivity of LA hydrogenation on different solid catalysts.

\begin{tabular}{|c|c|c|c|c|c|}
\hline Entry & Catalyst & Reaction Condition & LA conversion $(\%)$ & GVL selectivity (\%) & Refs \\
\hline 1 & $\mathrm{Ru} / \mathrm{C}$ & $\begin{array}{l}\text { triethylamine, } 3 \mathrm{~h} \text {, } \\
160^{\circ} \mathrm{C} \text {, formic acid }\end{array}$ & 87.3 & 92.5 & 1 \\
\hline 2 & $\mathrm{Re} / \mathrm{C}$ & $\begin{array}{l}\text { 1,4-dioxane, } 2 \mathrm{~h} \text {, } \\
150^{\circ} \mathrm{C}, 5.5 \mathrm{MPa} \mathrm{H}\end{array}$ & 7.0 & 80.0 & 2 \\
\hline 3 & $\mathrm{Ir} / \mathrm{C}$ & $\begin{array}{l}\text { 1,4-dioxane, } 2 \mathrm{~h}, \\
150^{\circ} \mathrm{C}, 5.5 \mathrm{MPa} \mathrm{H}\end{array}$ & 49.0 & 97.0 & 2 \\
\hline 4 & $\mathrm{Cu} / \mathrm{C}$ & $\begin{array}{c}\text { ethanol, } 6 \mathrm{~h}, 200^{\circ} \mathrm{C}, \\
2 \mathrm{MPa} \mathrm{H}_{2}\end{array}$ & 99.9 & 22.0 & 3 \\
\hline 5 & $\mathrm{Pd} / \mathrm{C}$ & $\begin{array}{c}0.1 \mathrm{MPa} \mathrm{H}_{2}, 50 \mathrm{~h} \\
265^{\circ} \mathrm{C}\end{array}$ & 99.9 & 90.0 & 4 \\
\hline 6 & $\mathrm{Pt} / \mathrm{C}$ & $\begin{array}{c}0.1 \mathrm{MPa} \mathrm{H}_{2}, 50 \mathrm{~h} \\
265^{\circ} \mathrm{C}\end{array}$ & 99.9 & 30.0 & 4 \\
\hline
\end{tabular}


Table S3. Grain size of Ni/C catalysts calculated by Scherrer formula.

\begin{tabular}{cccc}
\hline Samples & FWHM (111) & 2 Theta & DXRD (nm) \\
\hline $\mathrm{Ni} / \mathrm{C}-400$ & 0.520 & $44.44^{\circ}$ & 21.2 \\
$\mathrm{Ni} / \mathrm{C}-500$ & 0.558 & $44.44^{\circ}$ & 19.7 \\
$\mathrm{Ni} / \mathrm{C}-600$ & 0.503 & $44.44^{\circ}$ & 21.9 \\
\hline
\end{tabular}

The peak of nickel (111) crystal plane was selected as the object to calculate the grain size because of the lowest diffraction angle and strongest peak strength.

\section{Reference}

(1) Feng, J.; Gu, X. C.; Xue, Y. D.; Han, Y. W.; Lu, X. B. Production of gamma-valerolactone from levulinic acid over a $\mathrm{Ru} / \mathrm{C}$ catalyst using formic acid as the sole hydrogen source. Sci. Total. Environ. 2018, 633, 426-432.

(2) Manzer, L. E. Catalytic synthesis of alpha-methylene-gamma-valerolactone: a biomass-derived acrylic monomer. Appl. Catal. A 2004, 272, 249-256.

(3) Xu, Q.; Li, X. L.; Pan, T.; Yu, C. G.; Deng, J.; Guo, Q. X.; Fu, Y. Supported copper catalysts for highly efficient hydrogenation of biomass-derived levulinic acid and $\gamma$-valerolactone. Green Chem. 2016, 18, 1287-1294.

(4) Upare, P. P.; Lee, J. M.; Dong, W. H.; Halligudi, S. B.; Hwang, Y. K.; Chang, J. S. Selective hydrogenation of levulinic acid to $\gamma$-valerolactone over carbon-supported noble metal catalysts. $J$. Ind. Eng. Chem. 2011, 17, 287-292. 